\title{
Changes in the drug resistance of Staphylococcus aureus in a non-hospital population during a 20-year period
}

\author{
D. J. GOLDIE, V. G. AldER, AND W. A. Gillespie \\ From the Departments of Bacteriology, University of Bristol, and the United Bristol Hospitals
}

SYNOPSIS The antibiotic resistance of Staphylococcus aureus isolated in Bristol from primary skin $\stackrel{+}{+}$ sepsis and nasal carriers outside hospital was recorded between 1949 and 1969. The proportion of penicillinase-forming strains rose to about $60 \%$ but resistance to other antibiotics remained un-o common except for a peak about 1957, due to the spread of multiresistant phage-type 80 staphy-lococci. Reasons are discussed for the failure of other multiresistant staphylococci to increase ${ }_{\mathcal{D}}$ outside hospital.

Recently isolated strains from inside and outside hospital were tested with sulphonamide and@ trimethoprim. All were sensitive to trimethoprim but $5 \%$ of non-hospital strains and $40 \%$ of hospital strains were resistant to sulphonamide. It is suggested that sulphonamide-resistant staphylococcal $\bullet$ infections should not be treated with sulphonamide-trimethoprim mixtures because of the risk of breeding trimethoprim-resistant strains.

Most hospital staphylococci have been resistant to penicillin for a long time and many have become resistant to other antibiotics also. The incidence of penicillin resistance among staphylococci isolated outside hospitals has increased much more slowly but recent reports show that half or more of these strains are now penicillinase producers (Fallon, 1968; Price, O'Grady, Shooter, and Weaver, 1968). The incidence of resistance to other drugs among nonhospital staphylococci has been less fully documented, but experience in Bristol and elsewhere suggests that it is still low (Price et al, 1968).

In this paper we record changes in antibiotic resistance of coagulase-positive staphylococci isolated from the non-hospital population of Bristol between 1949 and 1969. Recently isolated strains were also tested with trimethoprim and sulphonamide as well as with antibiotics, and their sensitivity patterns were compared with recent hospital strains.

\section{Materials and Methods}

Coagulase-positive staphylococci from nasal carriers were isolated periodically in the casualty department of the Bristol Royal Infirmary, in a general practice, and from patients on the day of admission Received for publication 18 June 1970. to the Bristol Maternity Hospital. Strains from市 primary septic lesions of skin and subcutaneous tissues were isolated in the casualty department. Antibiotic sensitivity was tested by a disc method with the Oxford staphylococcus (NCTC 6571) as a control. Before 1960 strains were tested against benzylpenicillin, streptomycin, tetracycline, ando chloramphenicol. Subsequently neomycin and erythromycin discs were added and chloramphenicol 3 . was omitted. Strains from lesions collected in parto of 1969 and in January 1970 were tested also with discs containing sulphamethoxazole $50 \mu \mathrm{g}$ ando trimethoprim $2.5 \mu \mathrm{g}$ separately and together; in Oxoid sensitivity test agar with $7.5 \%$ lysed horse blood; and with methicillin discs $(10 \mu \mathrm{g})$ on nutrient agar at $30^{\circ} \mathrm{C}$ (Annear, 1968) or for a few strains salt ${ }^{\circ}$ agar (Churcher, 1968). Hospital strains from various $N$ lesions, isolated during the same period, were tested N similarly.

\section{Results}

The level of penicillin resistance stayed below $5 \%$ until 1952 then rose to $12 \%$ by 1955 (Figure).0 (Several years previously most hospital strains were⿸尹巳 already penicillin-resistant (Clarke, Dalgleish, ando Gillespie, 1952) and many were multiresistant. 


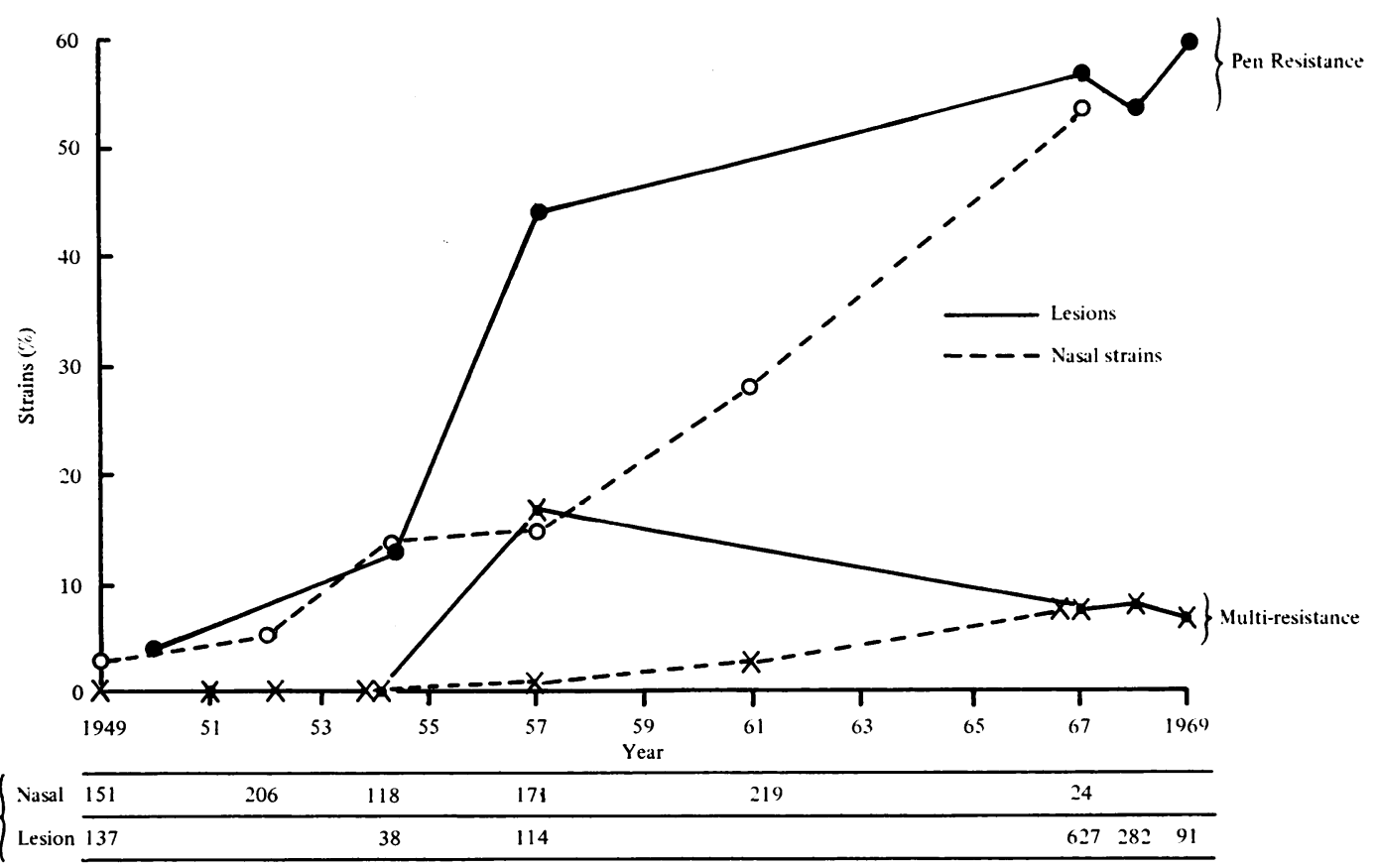

Fig. Percentage of multiresistant strains from nasal isolates and from those from lesions.

After 1954 the percentage of penicillin resistance increased rapidly among strains from lesions. This sharp increase was largely attributable to the spread of phage-type 80 staphylococci from hospitals (see below). Among nasal strains, the percentage of penicillin resistance increased more slowly but by 1967 it exceeded $50 \%$, a figure that did not differ materially from that of the strains isolated from lesions.

Resistance to other antibiotics in addition to penicillin (multiresistance) was first observed in lesion strains after 1954 and rose sharply to a peak of $16 \%$ in 1957. All but one of the multiresistant strains examined during this period belonged to phage type 80 and were resistant to penicillin, streptomycin, and tetracycline. Similar strains had recently caused much sepsis among inpatients in Bristol. Many infections also occurred in patients after discharge from hospital and in their close contacts, and were treated in the casualty department (Gillespie and Alder, 1957; Corner, Crowther, and Eades, 1960). The percentage of multiresistant strains among nasal isolates rose more slowly but by 1967 it became equal to the proportion in lesion strains which by then had fallen below $10 \%$ (Figure).

The resistance to several antibiotics of recently isolated hospital and non-hospital staphylococci in
Bristol is shown in Table I. Although the number of strains tested is small, it seems that methicillin resistance is still uncommon, even in hospital.

\begin{tabular}{lll}
\hline & In Hospital & Outside Hospital \\
\hline Number tested & 43 & 91 \\
Number resistant to & 36 & 55 \\
Penicillin & 21 & 2 \\
Streptomycin & 23 & 3 \\
Tetracycline & 8 & 2 \\
Erythromycin & 6 & 1 \\
Neomycin & - & $0^{1}$ \\
Methicillin & - &
\end{tabular}

Table I Antibiotic resistance of hospital and non-hospital Staph. aureus in 1969

${ }^{1}$ Forty-three non-hospital isolates were tested for methicillin resistance; these included all the multiresistant strains. A further 85 multiresistant strains, including $\mathbf{7 0}$ from inpatients, were examined before 30 June 1970 . Only one, from an inpatient, was methicillin resistant.

\section{SULPHONAMIDE AND TRIMETHOPRIM}

By inhibiting successive stages in bacterial metabolism these drugs, when administered simultaneously, have an enhanced action on bacteria that are sensitive to each drug separately. But if used to treat infections by strains that are already resistant to one of the drugs the combination will be less effective and there will be some danger of breeding 


\begin{tabular}{|c|c|c|c|}
\hline \multirow{2}{*}{$\begin{array}{l}\text { No. of } \\
\text { Strains } \\
\text { Tested }\end{array}$} & \multicolumn{3}{|c|}{ No. of Strains Resistant to: } \\
\hline & Sulphonamide & Trimethoprim & $\begin{array}{l}\text { Sulphonamide } \\
\text { Trimethoprim }\end{array}$ \\
\hline $\begin{array}{l}\text { Non-hospital } 1 \\
\text { Hospital }\end{array}$ & $\begin{array}{c}6(5 \%) \\
321(40 \%)\end{array}$ & $\begin{array}{l}\mathbf{0} \\
\mathbf{0}\end{array}$ & $\begin{array}{l}\mathbf{0} \\
\mathbf{0}\end{array}$ \\
\hline
\end{tabular}

Table II Resistance to sulphonamide and trimethoprim of hospital and non-hospital Staph. aureus in 1969 and 1970

resistance to the other drug. Table II shows that these considerations apply to staphylococci. None were resistant to trimethoprim but $40 \%$ of the hospital strains and $5 \%$ of the non-hospital ones were sulphonamide-resistant.

\section{Discussion}

Most staphylococci isolated from the general population of Bristol now produce penicillinase. The proportion of penicillinase-producing strains is apparently even greater in some other centres, for example, Glasgow (Fallon, 1968). But it is not certain how many strains form enough penicillinase to render infections clinically resistant to treatment with large doses of benzylpenicillin. Richmond, Parker, Jevons, and John (1964) found that the ability to form large amounts of penicillinase was closely associated with resistance to other antibiotics. Such strains are uncommon outside hospital (Price et al, 1968). These authors found that the response of superficial septic lesions in outpatients to treatment with penicillin was similar, whether or not the staphylococci produced penicillinase. An alternative explanation for these results was that antibiotic treatment may not materially influence the course of superficial infections. In any case, it would be unwise to rely on benzylpenicillin for the treatment of dangerous staphylococcal infections, eg, osteomyelitis, unless it were known that the organism did not produce any penicillinase. Moreover, the state of affairs observed by Richmond et al in 1964 may not continue indefinitely nor exist in all districts. The proportion of strong penicillinase producers among non-hospital staphylococci should be reviewed from time to time.

The failure of multiresistant staphylococci (with the notable exception of the type 80 strains) to increase much outside the hospital was in striking contrast to their behaviour inside it. Fallon (1969, personal communication) reports similar findings in Glasgow. The difference cannot be explained by differences in the proportions of the several antibiotics used inside and outside hospital but may be due to genetic changes that accompany the acquisi-
D. J. Goldie, V. G. Alder, and W. A. Gillespie tion of drug resistance by staphylococci. These $\frac{D^{*}}{\vec{*}}$ changes may be disadvantageous to resistant organisms outside hospital where they seldom come $\vec{F}$ into contact with antibiotics. Carriage of some of the plasmids mediating penicillinase production diminishes the growth of staphylococcal colonies (Rich- $\frac{\bar{T}}{\omega}$ mond, 1968). Some multiresistant staphylococci $\underset{\nabla}{\vec{\sigma}}$ belonging to phage group III do not colonize noses 2 as efficiently as other staphylococci (Thompson and के Gillespie, 1958). Lacey, Alder and Gillespie (1970) $\vec{\circ}$ found that group III strains, many of which were multiresistant and commonly found in hospital, $\vec{\omega}$ were killed by desiccation more quickly than other strains. Hence although they flourish in moist and? infected lesions in hospital they may not survive well in the nostrils and dry skin of healthy people outside. It should be noted, however, that Jessen, $f$ Rosendal, Bülow, Faber, and Eriksen (1969) report 은 a recent increase of staphylococci resistant to drugs other than penicillin in bacteraemia contracted out- T side hospital in Denmark. Strains from other non- $\frac{\mathbb{D}}{2}$ hospital sources in Denmark did not show a similar increase.

The value of sulphonamide with trimethoprim in $\overrightarrow{0}$ treating staphylococcal sepsis has not yet been fully assessed, but the existence of a few sulphonamideresistant staphylococci outside hospital, and a large number in hospital, argues the need for caution in treating staphylococcal infections until the sensitivity of the organism to both drugs has been ascer- $\frac{0}{\circ}$ tained. Widespread use of the combination to treat $\stackrel{\circ}{2}$ infections by sulphonamide-resistant staphylococci, $\overrightarrow{\overrightarrow{0}}$ or other infections in carriers of such staphylococci,, might provoke the development of resistance to trimethoprim. As always, new drugs should be? employed judiciously, especially against staphy-중 lococci which so often before have developed resist-: ance to other agents.

\section{References}

Annear, D. I. (1968). The effect of temperature on resistance of Staphylococcus aureus to methicillin and some other antibiotics Med. J. Aust., 1, 444-446.

Churcher, G. M. (1968). A screening test for the detection of methicillin-resistant staphylococci. J. clin. Path., 21, 213-217.

Clarke, S. K. R., Dalgleish, P. G., and Gillespie, W. A. (1952) Hospital cross-infections with staphylococci resistant to several antibiotics. Lancet, 1, 1132-1135.

Corner, B. D., Crowther, S. T., and Eades, S. M. (1960). Control of staphylococcal infection in a maternity hospital. Brit. med. J., 1, 1927-1929.

Fallon, R. J. (1968). Antibiotics in the treatment of E.N.T. infections? (Letter to Editor.) Brit. med. J., 4, 55.

Gillespie, W. A., and Alder, V. G. (1957). Control of an outbreak ofes staphylococcal infection in a hospital. Lancet, 1, 632-634.

Jessen, O., Rosendal, K., Bülow, P., Faber, V., and Eriksen, K. R. (1969). Changing staphylococci and staphylococcal infections $\bar{O}$ New Engl. J. Med., 281, 627-635.

Lacey, R. W., Alder, V. G., and Gillespie, W. A. (1970). The surviva呑 of Staphylococcus aureus on human skin: an investigation using mixed cultures. Brit. J. exp. Path., 51, 305-313. 


\section{The December 1970 Issue}

\section{THE DECEMBER 1970 ISSUE CONTAINS THE FOLLOWING PAPERS}

SI units in pathology

Trends in clinical pathologists A. G. SIGNY

Precautions adopted in a clinical chemistry laboratory as a result of an outbreak of serum hepatitis affecting hospital staff I. W. PERCY-ROBB, J. PROFFITT, AND L. G. WHITBY

Colistin, sulphamethoxazole, and trimethoprim in synergy against Gram-negative bacteria N. A. SIMMONS

Fatal infectious mononucleosis: A critical review HUGH G. PENMAN

The effect of diurnal variation on total plasma calcium concentration in normal subjects $M$. $R$. WILLS

A method for deriving normal ranges from laboratory specimens applied to uric acid in males $\mathbf{M}$. G. COOK, M. J. LEVELL, AND R. B. PAYNE

A rapid whole blood solubility test to differentiate the sickle-cell trait from sickle-cell anaemia R. G. HUNTSMAN, G. P. T. BARCLAY, D. M. CANNING, AND G. I. YAWSON

Some effects of mucopolysaccharide stains on platelet segregation J. R. O'BRIEN

Effects of the venom of the rhinoceros horned viper (Bitis nasicornis) on blood coagulation, platelet aggregation, and fibrinolysis N. MACKAY, J. C. FERGUSON, AND G. P. MCNICOL
J. F. Wilkinson, vol. 2, pp. 43-88. Academic Press, London and New York.

Richmond, M. H., Parker, M. T., Jevons, M. P., and John, M. (1964). High penicillinase production correlated with multiple antibiotic resistance in Staphylococcus aureus. Lancet, 1, 293-296.

Thompson, M. E. M., and Gillespie, W. A. (1958). Nasal carriage of Staphylococcus aureus by nurses. J. Path. Bact., 75, 351-355.
Pharmacological enhancement of fibrinolytic activity and ${ }^{125}$ I-fibrinogen survival J. A. HICKMAN

Assay of anti-D using the Technicon AutoAnalyzer and the international standard anti-D typing serum W. J. JUDD AND W. J. JENKINS

An evaluation of photoelectric haemoglobinometers S. M. LEWIS with the technical assistance of B. J. BURGESS

Intrafollicular amyloid in primary hyperparathyroidism P. W. LEEDHAM AND D. J. POLLCCK

The use of SI in reporting results in pathology

\section{Technical methods}

A two-dimensional chromato-bioautographic method for complete separation of individual plasma cobalamins J. C. LINNELL, H. A-A. HUSSEIN, AND D. M. MATTHEWS

Rvaluation of methods for preparing pure lymphocyte suspensions from peripheral blood CAROL A. EVANS AND VALERIE L. MIDDLETON

A technique for rapid isolation of macrophages from guinea-pig peritoneal exudates M. KNOWLES AND D. HUGHES

Letter to the Editor

The Association of Clinical Pathologists: 85th General Meeting

Book reviews

Copies are still available and may be obtained from the PUBLISHING MANAGER, BRITISH MEDICAL ASSOCIATION, TAVISTOCK SQUARE, WC1H 9JR price $21 s$. 